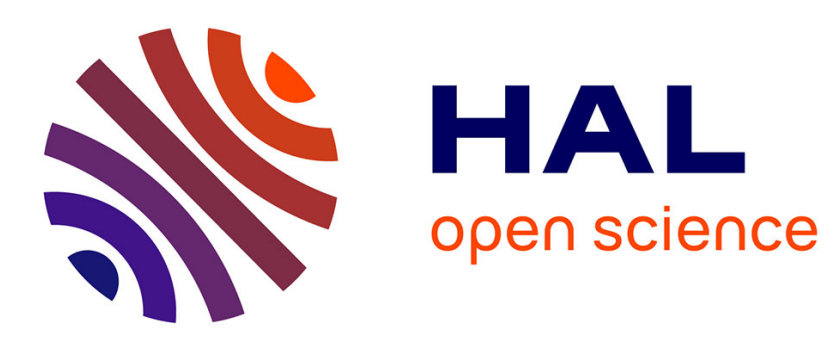

\title{
Estimation of the public benefits of urban water supply improvements in Ethiopia: a choice experiment \\ Solomon Tarfasa, Roy Brouwer
}

\section{To cite this version:}

Solomon Tarfasa, Roy Brouwer. Estimation of the public benefits of urban water supply improvements in Ethiopia: a choice experiment. Applied Economics, 2011, 45 (09), pp.1099-1108. 10.1080/00036846.2011.613793 . hal-00762812

\section{HAL Id: hal-00762812 \\ https://hal.science/hal-00762812}

Submitted on 8 Dec 2012

HAL is a multi-disciplinary open access archive for the deposit and dissemination of scientific research documents, whether they are published or not. The documents may come from teaching and research institutions in France or abroad, or from public or private research centers.
L'archive ouverte pluridisciplinaire HAL, est destinée au dépôt et à la diffusion de documents scientifiques de niveau recherche, publiés ou non, émanant des établissements d'enseignement et de recherche français ou étrangers, des laboratoires publics ou privés. 




\section{Estimation of the public benefits of urban water supply improvements in Ethiopia: a choice experiment}

\begin{tabular}{|r|l|}
\hline Journal: & Applied Economics \\
\hline Manuscript ID: & APE-2011-0059 \\
\hline Journal Selection: & Applied Economics \\
\hline Author: & O9-Feb-2011 \\
\hline Complete List of Authors: & $\begin{array}{l}\text { Tarfasa, Solomon; Hawassa University, Economics } \\
\text { Brouwer, Roy; Institute for Environmental Studies, Vrije Universiteit } \\
\text { Amsterdam }\end{array}$ \\
\hline JEL Code: & $\begin{array}{l}\text { H42 - Publicly Provided Private Goods < H4 - Publicly Provided } \\
\text { Goods < H - Public Economics, I31 - General Welfare|Basic } \\
\text { Needs|Living Standards|Quality of Life < I3 - Welfare and Poverty } \\
<\text { I - Health, Education, and Welfare, L95 - Gas } \\
\text { Utilities|Pipelines|Water Utilities < L9 - Industry Studies: } \\
\text { Transportation and Utilities < L - Industrial Organization, Q25 - } \\
\text { Water < Q2 - Renewable Resources and } \\
\text { Conservation|Environmental Management < Q - Agricultural and } \\
\text { Natural Resource Economics, Q51 - Valuation of Environmental } \\
\text { Effects < Q5 - Environmental Economics < Q - Agricultural and } \\
\text { Natural Resource Economics }\end{array}$ \\
\hline Keywords: & $\begin{array}{l}\text { Water supply, Choice experiment, Domestic water demand, } \\
\text { Willingness to pay, Market segmentation }\end{array}$ \\
\hline
\end{tabular}




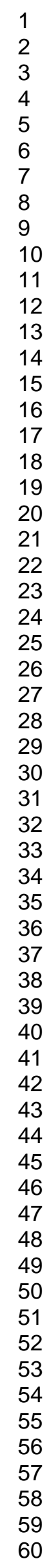

SCHOLARONE $^{m}$
Manuscripts

10

11

13

14

15

16

18

19

20

22

23

25

26

27

29

30

32

33

34

35

36

39

40

41

42

44

45

46

47

48

50

51

52

53

54

56

57

58

60

Editorial Office, Dept of Economics, Warwick University, Coventry CV4 7AL, UK 


\title{
Estimation of the public benefits of urban water supply improvements in Ethiopia: a choice experiment
}

\author{
Solomon Tarfasa ${ }^{1}$ and Roy Brouwer ${ }^{2}$ \\ ${ }^{1}$ Department of Economics, Hawassa University, Hawassa, Ethiopia \\ ${ }^{2}$ Department of Environmental Economics, Institute for Environmental Studies, VU University \\ Amsterdam, the Netherlands
}

\begin{abstract}
Improving existing drinking water supply services in developing countries depends crucially on available financial resources. Cost recovery rates of these services are typically low, while demand for more reliable services is high and rapidly growing. Most stated preference based demand studies in the developing world apply the contingent valuation method and focus on rural areas. This study examines household willingness to pay for improved water supply services in a choice experiment in an urban area in Ethiopia, a country with the lowest water supply coverage in Sub-Saharan Africa. The design of the choice experiment allows estimation of the value of both drinking water supply reliability and safety. The estimated economic values can be used in policy appraisals of improved supply investment decisions. Despite significant income constraints, households are willing to pay up to 80 percent extra for improved levels of water supply over and above their current water bill. Women and households living in the poorest part of the city with the lowest service levels value the improvement of water quality most. As expected, also averting behavior and expenditures play an important role.
\end{abstract}

Key Words: Water supply, Choice experiment, Domestic water demand, Ethiopia, Market segmentation, Willingness to pay 


\section{Introduction}

Safe domestic water supply is an essential component of primary health care and plays a vital role in poverty alleviation. Inadequate water supply and sanitation services impact upon the lives of billions of poor people in the developing world (World Bank, 2004). Two in every ten persons lack access to safe water supply, five have inadequate sanitation, and nine do not have their wastewater treated. Yet, these estimates are believed to underestimate the extent of the drinking water supply problem. In many countries where water supply systems have been installed, the quality of the services provided is poor. Many consumers who are connected face unreliable water supply and when available, it is often not safe to drink (World Bank, 2004).

Water supply services in Ethiopia are among the lowest in Africa, with an average consumption of only 15 liter per capita per day in urban areas, which is far below the World Health Organization (WHO) standard of 45 liters per person per day. Safe domestic water supply is estimated to be available to 36 percent of the population in rural areas and 80 percent in urban areas (EWSRFA, 2004). According to the WHO, Ethiopia had the lowest level of water supply coverage in SubSaharan Africa in 2000 (39\% compared to an average of $56 \%$ in Sub-Saharan Africa) and the second-lowest level of sanitation coverage (EPER, 2004). Unprotected water supply sources are one of the most important problems related to water supply quality. Consequently, a majority of the Ethiopians use unsafe and polluted water and are, as a result, exposed to a large variety of water-borne diseases. This is especially the case for the rapidly growing urban population.

Besides limited protection of water supply sources, financial constraints also play an important role in the current state of water supply in Ethiopia. Investment and operation costs of domestic water supply facilities are only partly covered by the consumers (15\%). The central government contributes more or less the same as the consumers, but the majority of the costs (70\%) are funded 
by financial sources from outside Ethiopia, primarily through international aid (Teshome, 2007). There exists a huge gap between the finance required to maintain and operate the existing water supply system and the revenues generated through the existing water tariff system and other sources to match the growing demand for more reliable and safe water supply. Hence, additional funding is needed.

The main objective of this study is to assess household willingness to pay extra for improved water supply services in an urban centre in Ethiopia. Hawassa is the $8^{\text {th }}$ largest city of Ethiopia with a population of almost 160 thousand people (CSA, 2007) and located almost $300 \mathrm{~km}$ south of the capital Addis Ababa. Little to no empirical evidence is available in Ethiopia on how much urban households would be willing to pay extra to improve water supply services for use in water supply investment decision-making or tariff setting. The only published stated preference study by Kinfe and Berhanu (2007) asked 240 randomly selected households in Addis Ababa in a contingent valuation survey for their willingness to pay (WTP) for a bucket of extra water. They found positive WTP values ranging between 15 and 20 US dollar (USD) cents per bucket (i.e. approximately 1.5-2.0 USD cents per liter) depending on the estimated statistical model. Probably best known in the area of contingent valuation of drinking water supply in developing countries is the work by Whittington (e.g. Whittington et al., 1990; Whittington, 1998). However, most of these studies were conducted in rural areas. Very few applied contingent valuation studies exist for urban areas in the developing world, exceptions being Soto Montes de Oca and Bateman (2006) and Vásquez et al. (2009) in Mexico.

In the study presented here, we apply a more advanced stated preference choice experiment (e.g. Blamey et al., 1999; Scarpa et al., 2007), where households are asked to choose between different policy scenarios of improved water supply services at different water price levels. In the design of 


\section{The choice model}

Preferences are modeled in terms of McFadden's (1974) Random Utility Model (RUM), allowing for a separation of utility $\left(U_{i j t}^{c}\right)$ into a deterministic part $\left(V_{i j t}^{c}\right)$ and a stochastic part $\left(\varepsilon_{i j t}^{c}\right)$. Choice experiments fall in the class of attribute-based methods in which the deterministic part of utility for individual $i$ for good $j$ in choice task $t$ is described in (1) as a linear function of its attributes $X_{i j t}$ and other explanatory variables $Z_{i j t}$ (Train, 2003):

$$
U_{i j t}=V_{i j t}+\varepsilon_{i j t}=\beta X_{i j t}+\alpha Z_{i j t}+\varepsilon_{i j t} \quad \forall j \in D_{i t}
$$

In each choice task the respondent is presented with a limited set of policy proposals $D_{i t}$, each proposing an improvement in domestic water supply and water quality. The stochastic term is assumed to follow an IID extreme value distribution of type 1. 
To account for preference heterogeneity, the preference parameters for the non-price attributes are allowed to vary across respondents, applying different mixing distributions. Equation (2) describes the mixed logit (ML) probability of individual $i$ selecting alternative $j$ in choice task $t$ over other choice alternatives $k$. The utility coefficients $\beta$ vary according to individual (hence $\beta_{\mathrm{i}}$ ) with density $\Delta\left(\beta_{i} \mid b\right)$ for the non-price attributes. This density can be a function of any set of parameters and represents in this case the mean and covariance of $\beta$ in the sample population.

$$
P_{i j t}=\int\left(\frac{\exp \left[\left(\beta_{i} X_{i j t}+\alpha Z_{i j t}\right)\right]}{\sum_{j \in D} \exp \left[\left(\beta_{i} X_{i k t}+\alpha Z_{i k t}\right)\right]}\right) \Delta\left(\beta_{i} \mid b\right) d \beta_{i} \quad \forall j \in D_{i t}
$$

ML-models assume heterogeneity to be continuous over the interval spanned by the assumed distribution for the preference parameters (Scarpa et al., 2005). Treating preference parameters as random variables requires estimation through simulated maximum likelihood. Procedurally, the maximum likelihood algorithm searches for a solution by simulating draws from distributions with given means and standard deviations. Probabilities are calculated by integrating the joint simulated distribution. Recent applications of ML-models have shown that this model is superior to the standard multinomial logit model in terms of overall fit and accuracy of welfare estimates (e.g., Breffle and Morey, 2000; Layton and Brown, 2000; Morey and Rossmann, 2003; Provencher and Bishop, 2004; Brouwer et al., 2010a).

Mixed logit models account for respondent differences (preference heterogeneity) and repeated choices (Train, 2003). Even if unobserved heterogeneity is accounted for in a ML-model, the model may fail to explain the sources of heterogeneity (Hynes et al., 2008). To this end, interactions of respondent specific household characteristics can be included with choice specific 
Error component (EC) models furthermore accommodate correlation between the utilities of alternatives (Brownstone and Train, 1999). Correlation between alternatives is accounted for by including an error component with zero mean in the utility function specification to allow for heteroscedasticity between those alternatives that are likely to be correlated. Scarpa et al. (2005) recommend applying EC models when comparing less familiar (hypothetical) alternatives with better known (existing) ones (the opt-out in this case).

Finally, if a price attribute is included in the choice experiment, welfare estimates can be derived (e.g., Hensher et al., 2005). The welfare measure represents the monetary value arising from a change in the bundle of water supply services, also referred to as the consumer surplus (CS). In the study presented here, the economic welfare implications are estimated of different water supply improvement policy scenarios. We now turn to the design of the choice experiment.

\section{The experiment}

The choice experiment was designed in collaboration with the Hawassa Water Supply and Sewerage Office (HWSSO), who is responsible for maintaining and operating the water system in the city and collecting water fees from connected domestic households. Most consumers have a private connection ( $73 \%$ of all water consumption), followed by public fountains ( $20 \%$ of the total water consumption) and yard connections where one or more taps are installed in a household's 
backyard with a water meter ( $7 \%$ of the total consumption). In this study only those customers were interviewed who have a private connection.

The HWSSO employs a progressive monthly water tariff system that is based on the amount of water consumed by the customer. For customers consuming less than $5 \mathrm{~m}^{3}$ per month the tariff is 1 Birr $^{1}$, for those consuming between 5 and $10 \mathrm{~m}^{3}$ the tariff is 3.4 Birr. Consumption levels between 10 and $20 \mathrm{~m}^{3}$ have a tariff of 4.4 Birr and for amounts greater than $20 \mathrm{~m}^{3}$ the tariff is 5.5 Birr.

In the choice experiment, respondents were presented a series of possible water supply improvement scenarios, differing in the level of water supply reliability and water quality, at different increases in their water fee. Respondents were asked to choose their most preferred policy alternative. Based on expert interviews and focus group discussions, two relevant attributes for the water supply services were selected together with their levels. Domestic water supply was extended with 1, 2 or 3 days per week and water quality was qualified as either needing boiling for infants only or no boiling at all. In addition, five price levels were identified: an increase in the household's monthly water bill of 3, 5, 10, 15 or 20 Birr.

Alternative policy scenarios are created by combining these three variables based on their different attribute levels. Because respondents cannot be shown all different choice options, the number of possible combinations was reduced to 24 choice sets of 12 choice tasks each based on an orthogonal fractional factorial design generated in the statistical software SPSS, enabling the estimation of main effects and two-way interactions. Each respondent was randomly shown one of these 24 choice sets of 12 choice cards. Each choice card shows two hypothetical choice

\footnotetext{
${ }^{1}$ Birr is Ethiopia's national currency. At the time of the study, 1 Birr was equal to approximately 0.06 USD.
} 


\section{INSERT TABLE 1 HERE}

The design of the choice experiment was first pretested and subsequently implemented in June 2010 through 170 in-person interviews in three zones in Hawassa city distinguished by the HWSSO: Misrak Wukro, Manaharia and Mahal Piasa. The response rate was 100 percent, which is not unusual for this kind of stated preference research in a developing country (Whittington, 1998). Although up-to-date statistical information about household characteristics is not available for the different zones, the zones differ considerably in terms of their socio-economic status. Misrak Wukro is generally considered the poorest part of the city, whereas households in Manaharia and Mahal Piasa are better off. In each zone, first households with a private compound were identified and secondly from this a random selection chosen. A third sample selection criterion was that a more or less equal share of men and women in the households was to be interviewed to test for possible gender effects in domestic water supply valuation. Trained local enumerators were used for the interviews. After data screening, 145 of the 170 interviews could be used in the analysis (50 from Misrak Wukro, 52 from Manaharia and 43 from Mahal Piasa). The results are presented in the next section. 


\section{Results}

\subsection{Sample characteristics}

Table 2 reports the socio-economic characteristics of the interviewed households. A majority of the respondents $(63 \%)$ is female and respondents are, on average, 34 years old. Respondents were between 18 and 80 years of age. Average monthly household income is USD 145. Given the average household size, this equals a monthly per capita net income of USD 26. This is lower than the World Bank's international (PPP-adjusted) poverty line of USD 1.25 per day.

\section{INSERT TABLE 2 HERE}

Turning to the household's domestic water supply characteristics, consumption varies between 10 and 800 liters per day. On average, a household has 4 days per week access to drinking water supply and they pay USD 2.2 per month for their water bill. This is 1.5 percent of their monthly household income. Most households (58\%) also spend every month a considerable amount of money on substitutes such as bottled water.

\subsection{Aggregate choice model}

All 145 respondents are interested in and willing to pay extra for improved water supply services and completed all 12 choice tasks. No protest voters were encountered in the data, i.e. respondents who consistently chose the opt-out alternative on all choice occasions. Across all 1740 choice occasions, the opt-out was chosen in 12 percent of the cases. As expected in unlabelled choice experiments, an equal distribution of choices is found between the two hypothetical alternatives. Choice behaviour was modelled using a combination of random parameter and error component models, accounting for the panel data structure of the choice model. For efficiency purposes, the 
models were estimated using a Halton sequence of 100 replications in a quasi-Monte Carlo maximum likelihood simulation (Bhat, 2001) in NLOGIT version 4.0.

Two models are presented in Table 3. The first model only includes the attributes, whereas the second model includes additional socio-demographic respondent characteristics. Several possible interactions between the attributes and socio-demographic respondent characteristics were tested for their statistical significance. The model that came out best from a statistical point of view after systematic testing of all possible interactions, i.e. including statistically significant variables only at the 10 percent level, is presented in Table 2.

\section{INSERT TABLE 3 HERE}

The models are highly significant. The outcome of the $\chi^{2}$ is 1302.473 with 7 degrees of freedom and 1506.455 with 11 degrees of freedom for the first and second model respectively. The estimated error component is significant in both models at the one percent level, indicating that respondents perceived the two hypothetical alternatives distinctly from the existing situation. The significant positive outcome of the alternative specific constant (ASC) in both models implies that respondents prefer a change instead of no change from the current situation.

The attribute parameters are highly significant and have the expected signs. Households value the availability of additional drinking water supply and improved quality. An increase in the water bill is, as expected, valued negatively, implying that the utility of the households decreases as the monthly water bill increases. Water supply is included as a continuous variable and water quality as a dummy variable with the value one if the water needs no boiling. The attributes are characterized by significant preference heterogeneity. The standard deviations of the water supply 
service attributes are also significant and sizeable, indicating that we captured unobserved heterogeneity in the random parameter specification. The standard deviation for water supply was best captured by a Normal distribution and the standard deviation for water quality by a Uniform distribution (e.g., Hensher et al., 2005). Based on these coefficient estimates marginal WTP and standard deviations were calculated using the Krinksy and Robb (1986) procedure. Marginal WTP for one extra day of domestic water supply is USD 0.3 per month, while marginal WTP for water that requires no boiling is USD 1.2 per month. This is an increase in the average current water bill of 14 and 53 percent respectively.

The second model shows that including additional explanatory variables significantly improves the model fit. The value of the log likelihood function is reduced further compared to the first model, while the pseudo R-squared increases to almost 40 percent, which is high for this type of models based on cross-section data. The size of the impact of all the attributes (and the ASC) is reduced through the inclusion of the theoretically expected variable household income (richer households are more likely to be willing to pay extra for improved water supply services than poorer households), but also variables such as the zone in which the respondent lives (respondents living in the poorest zone Misrak Wukro attach significantly more value to the improvement of water supply) and current spending on bottled water as an alternative to water supplied by the HWSSO (respondents who spend on average more money on bottled water value a water quality improvement significantly more than respondents who spend less money on bottled water). As expected, women who usually cook and take care of the children in the household value water quality improvements more than men to a level where it does not have to be boiled anymore for infants. No significant effect could be detected for any of the other socio-demographic respondent characteristics (e.g., age, education or household composition). 


\subsection{Tests of preference stability}

One of the main assumptions underlying stated preferences is that respondents know their preferences and that these preferences are stable and coherent (e.g. Brown et al. 2008). This implies that individuals consistently know their preference ordering for a set of goods or services and the rate at which they are willing to trade off good characteristics, such as price and quality. Hence, from a set of alternatives the individual is assumed to be capable of selecting the most preferred one based on its characteristics. Choice behavior at the start of the experiment is expected to be consistent with choice behavior at the end of the experiment (Brouwer et al., 2010b). However, lack of familiarity and experience with the good or service involved and the hypothetical choice setting may undermine these a priori assumptions (Shaikh et al. 2007).

We examine possible learning and preference refinement effects by comparing the scale parameter over the choice sequence using the Swait and Louviere (1993) procedure. The scale parameter is inversely related to the variance of the error term (Louviere et al., 2000). If the scale increases, variance decreases, that is, people are making a more accurate choice between the presented alternatives. Obtaining estimates for the scale parameter therefore provides insight into preference refinement during a choice sequence (Holmes and Boyle 2005). Through repetition respondents are expected to be capable of making more precise and consistent decisions, because they learn about the survey format, the associated hypothetical market and their own preferences (List 2003).

We test whether the utility parameters $\beta$ and the confounded scale parameters $\mu$ in the estimated choice model presented in Table 2 remain the same across the 12 choice tasks. To this end, a pairwise comparison is performed between the choice tasks. We split the 12 choice tasks in four sets of three tasks. In a first step, the estimated ML-model from Table 2 provides efficient estimates for $\mu^{1} \beta^{1}, \mu^{2} \beta^{2}, \mu^{3} \beta^{3}$ and $\mu^{4} \beta^{4}$ and a likelihood function for each set of three choice tasks. Then the scale 
parameter of, for example, the first set of three choice tasks is normalized to $\mu^{1}=1$ for identification purposes. In a second step, a pooled model including the first and second set of choice tasks is estimated, which has the effect of imposing equality on the preference parameters $\left(\beta^{1}=\beta^{2}\right)$. In this model the relative scale parameter $\mu^{2} / \mu^{1}$ is, however, not set equal to 1 . A search procedure over a range of relative scale parameters is applied to estimate the combination of scale and pooled preference parameters providing the best model fit. At each possible relative scale parameter the data for the second set of choice tasks are rescaled such that a ML-model can be estimated. After the best fit model has been identified, a standard chi-square (Likelihood Ratio) test using the log likelihoods of the models from step 1 and the best fit model of step 2 can be used to test the difference between the preference parameters in the two choice sets under the null hypothesis that they are the same.

The third step tests for differences in scale across choice tasks. In principle this step is conditional on accepting the mentioned chi-square test. It requires the estimation of a ML-model for the same pooled model as in step 2, but with equality imposed on both preference and scale parameters this time $\left(\beta^{1}=\beta^{2}\right.$ and $\left.\mu^{1}=\mu^{2}\right)$. Again a chi-square test can be applied to compare the log likelihood of the estimated model to the log likelihood of the pooled model with varying scale parameters. The results of this test procedure are presented in Table 4.

\section{INSERT TABLE 4 HERE}

When comparing the estimated choice models between the four sets of choice tasks, both the null hypothesis of equality of preference parameters and scale parameters are rejected at the 10 percent significance level, except the scale parameter between the first and second choice set (last column in Table 3). Hence, choice behavior at the start of the choice experiment is different compared to 
Comparing the estimated choice models across the four choice sets, the model based on the third choice set is the only model where one of the attributes (extra days of water supply) is not statistically significant at the 10 percent level. The attributes are statistically significant in all other choice sets, including the increase in the water bill. Variation across the choice models is primarily found in the interaction terms between the attribute water supply and aversion cost and the attribute water quality and female respondents. These results suggest that overall the attributes remain fairly stable, but not the influence of the socio-demographic characteristics on choice behavior.

\subsection{Economic welfare measures for water supply improvement policy scenarios}

The welfare implications of different water supply improvement policy scenarios were calculated based on the estimated model in Table 2 including household characteristics. Currently, consumers receive, on average, drinking water four days per week. In most cases, they have to boil the water before they can drink it. Table 5 presents the estimated mean WTP values associated with improvements in urban water supply services for the average respondent. Standard errors are presented in brackets and are based on the Krinsky-Robb (1986) procedure. WTP for the water supply improvement policy scenarios are presented both in local currency (Birr) and US dollars.

\section{INSERT TABLE 5 HERE}


In case only water supply improves, not water quality, urban households are willing to pay, on average, between 25 and 50 percent extra over and above their current monthly water bill of 36.2 Birr (USD 2.2). If water quality improves at the same time, the increase in the water bill households would be willing to pay varies between 60 and 80 percent depending on the extra days of domestic water supply.

If the sample is representative, these values can be aggregated across the population from which it was drawn in order to calculate a total economic value for the policy scenarios. This total economic value can subsequently be compared with the necessary investment and maintenance costs for the improvement of current water supply services in the city of Hawassa. Based on the factors that turned out to be statistically significant in the second choice model presented in Table 2, women are expected to benefit most from improvement scenarios which include water quality. Given the fact that we also found a significant spatial effect for one of the zones, investments in water supply improvement will be most beneficial to households living in the poorest zone Misrak Wukro.

\section{Conclusions}

Reliable water supply services are of paramount importance to the expanding urban populations in the developing world. Improving existing water supply services depends crucially on available financial resources. Cost recovery rates of water supply services provided by public utilities in developing countries are typically low, while demand for more reliable services is high and rapidly growing. In this study we examined public preferences for improved water services in an urban area in a country with the lowest water supply coverage in Sub-Saharan Africa with the aim to estimate the non-market value of water supply service improvements. This economic value can be used in policy and project appraisals of improved supply investment decisions. 
The study adds to the limited stock of water supply reliability valuation studies. A number of contingent valuation studies exist focusing on willingness to pay for improved water supply services in developing countries, in particular in rural areas and few in urban zones. Almost no studies exist that apply choice experiments. Those that do focus on WTP to avoid domestic water restrictions or improve environmental river quality in developed countries. In the choice experiment in this study we estimated compensating surplus welfare measures by asking a random sample of households in Hawassa, Ethiopia for their willingness to pay for improved water supply services, both in terms of quantity and quality. Currently, households have, on average, 4 days per week access to drinking water, and consume almost 100 liters per day for which they pay USD 2.2 per month. Based on the average household size, daily per capita consumption is only 18 liters. This is very low compared to the estimated average per capita consumption levels in the rest of the developing world (UNESCO, 2003). Almost 60 percent of the interviewed households pay every month an equal amount of money for alternative drinking water sources such as bottled water. All households boil their water before they drink it. Water quality is not constant and often unsafe to drink.

Despite significant income constraints, all households appeared to be willing to pay substantially extra for improved levels of water supply, especially those households living in the poorest part of the city with the lowest service levels and who pay more for alternative water sources such as bottled water. Although estimated preference parameters vary throughout the choice sequence in the choice experiment, choice variability decreases significantly towards the end of the choice experiment. This suggests the presence of learning effects whilst going through the choice tasks. Mean WTP for more reliable water supply varies between 25 and 50 percent over and above the current household water bill. If water quality is improved at the same time, this results in an almost twice as high additional WTP depending on the extra days of water supply. Women who take care 
of infants in the household value the improvement of water quality to a level where boiling for infants is not necessary anymore most.

Aggregating the estimated individual household WTP values across the total number of households in Hawassa (approximately 12,500) under the assumption that the survey sample is representative yields a rough indicator of the total benefits of future investment plans in improved water supply services. The value of these benefits vary from USD 90,000 per year if water supply services are improved by one day only to USD 165,000 per year if water supply is improved by three days to, on average, seven days per week. If water quality is improved in the latter case at the same time, the value of the total benefits equals USD 270,000. Discounted over a 25-year time period at a discount rate of 10 percent this amounts to a present value of approximately USD 2.5 million. This discounted value can be compared to the capital costs of any future investment decision in improved water supply services in the city. 


\section{References}

Bateman, I.J., Carson, R.T., Day, B., Hanemann, W.M., Hanley, N.,Hett, T., Jones-Lee, M., Loomes, G., Mourato, S., Özdemiroğlu, E., Pearce, D.W., Sugden, R., Swanson, S., 2003. Guidelines for the Use of Stated Preference Techniques for the Valuation of Preferences for Nonmarket Goods. Edward Elgar, Cheltenham.

Bhat, C.R., 2001. Quasi-random maximum simulated likelihood estimation of the mixed multinomial logit model. Transportation Research Part B. 35, 677-693.

Brouwer, R., Martín-Ortega, J. and Berbel, J., 2010a. Spatial preference heterogeneity: a choice experiment. Land Economics. 86(3), 552-568.

Brouwer, R., Dekker, T., Rolfe, J. and Windle, J., 2010b. Choice certainty and consistency in repeated choice experiments. Environmental and Resource Economics. 46, 93-109.

Brown, T.C., Kingsley, D., Peterson, G.L., Flores, N.E., Clarke, A., Birjulin, A., 2008. Reliability of individual valuations of public and private goods: choice consistency, response time, and preference refinement. Journal of Public Economics. 92, 1595-1606.

Blamey, R., Gordon, J. and Chapman, R., 1999. Choice modelling: assessing the environmental values of water supply options, Australian Journal of Agricultural and Resource Economics. 43(3), $337-357$. 
Breffle, W. and Morey, E., 2000. Investigating Preference Heterogeneity in a Repeated DiscreteChoice Recreation Demand Model of Atlantic Salmon fishing. Marine Resource Economics. 15, 120.

Brownstone, D. and Train, K., 1999. Forecasting new product penetration with flexible substitution patterns. Journal of Economics. 89, 109-129.

CSA, 2007. Census 2007 Tables. Central Statistical Agency of Ethiopia, Addis Abeba.

EPER, 2004. Ethiopia Public Expenditure Review. Unpublished Report on Ethiopia Public Expenditure.

EWSRFA, 2004. Ethiopia Water Supply Sector Resource Flows Assessment. Sector Finance Working Papers, V. 2, No. 10.

Hensher, D.A., Rose, J.M. and Greene, W.H., 2005. Applied choice analysis. A primer. Cambridge University Press, Cambridge.

Hensher, D.A., Shore, N. and Train, K., 2006. Water Supply Security and Willingness to Pay to Avoid Drought Restrictions. The Economic Record. 82(256), 56-66.

Holmes, T.P. and Boyle, K.J., 2005. Dynamic learning and context-dependence in sequential, attribute-based stated-preference valuation questions. Land Economics. 81, 114-126. 
Hynes, S., Hanley, N. and Scarpa, R., 2008. Effects on welfare measures of alternative means of accounting for preference heterogeneity in recreational demand models. American Journal of Agricultural Economics. 90(4), 1011-1027.

Kinfe, G. and Berhanu, A., 2007. Valuing Water Supply Service Improvements in Addis Ababa. Ethiopian Journal of Economics. 16(2), 50-72.

Krinsky, I., and Robb, A.L., 1986. On approximating the statistical properties of elasticities. Review of Economics and Statistics. 68, 715-719.

Layton, D. and Brown, G., 2000. Heterogeneous preferences regarding global climate change. Review of Economics and Statistics. 82, 616-624.

List, J.A., 2003. Does market experience eliminate market anomalies? Quarterly Journal of Economics. 41-72.

Louviere, J.J., Hensher, D.A. and Swait, J.D., 2000. Stated choice methods: analysis and application. Cambridge: Cambridge University Press.

McFadden, D., 1974. Conditional logit analysis of qualitative choice behaviour. In: P. Zarembka (Ed.), Frontiers in Econometrics. Academic Press, New York, 105-142.

Morey, E.R. and Rossmann, K.G., 2003. Using Stated-Preference Questions to Investigate Variations in Willingness to Pay for Preserving Marble Monuments: Classic Heterogeneity, Random Parameters, and Mixture Models. Journal of Cultural Economics. 27(4), 229. 
Provencher, B. and Bishop, R. C., 2004. Does accounting for preference heterogeneity improve the forecasting of a random utility model? Journal of Environmental Economics and Management. 48(1), 793-810.

Revelt, D. and Train, K., 1998. Mixed logit with repeated choices: households' choice of appliance efficiency level. Review of Economics and Statistics. 53, 647-657.

Scarpa, R., Willis, K.G., and Acutt, M., 2005. Individual-specific welfare measures for public goods: a latent class approach to residential customers of Yorkshire Water. In: Koundouri. P. (ed.). Econometrics informing natural resource management. Edward Elgar Publishers, Cheltenham, UK.

Scarpa, R., Willis, K.G., and Acutt, M., 2007. Valuing Externalities from Water Supply: Status Quo, Choice Complexity and Individual Random Effects in Panel Kernel Logit Analysis of Choice Experiments. Journal of Environmental Planning and Management. 50(4), 449-466.

Shaik, S.L., Sun, L., and van Kooten, G.C., 2007. Treating respondent uncertainty in contingent valuation: A comparison of empirical treatments. Ecological Economics. 62, 115-125.

Soto Montes de Oca, G. and Bateman, I. J., 2006. Scope sensitivity in households' willingness to pay for maintained and improved water supplies in a developing world urban area: Investigating the influence of baseline supply quality and income distribution upon stated preferences in Mexico City. Water Resources Research. 42, W07421, doi:10.1029/2005WR003981.

Swait, J. and Louviere, J., 1993. The role of the scale parameter in the estimation and comparison of multinomial logit models. Journal of Marketing Research. 30(3), 305-314. 
Teshome A., 2007. Prospects and Challenges of Water Supply and Sanitation in Ethiopia with respect to MDG. Proceedings of the Fifth International Conference on the Ethiopian Economy: Vol. III.

Train, K., 2003. Discrete choice models with simulation. Cambridge University Press.

UNESCO, 2003. Water for People, Water for Life - UN World Water Development Report (WWDR). UNESCO Publishing, Paris.

Vásquez, W.F., Mozumder, P., Hernández-Arce, J. and Berrens, R.P., 2009. Willingness to pay for safe drinking water: Evidence from Parral, Mexico. Journal of Environmental Management. 90(11), 3391-3400.

Whittington, D., Briscoe, J., Mu, X. and Barron, W., 1990. Estimating the Willingness to Pay for Water Services in Developing Countries: A Case Study of the Use of Contingent Valuation Surveys in Southern Haiti. Economic Development and Cultural Change. 38(2), 293-311.

Whittington, D., 1998. Administering contingent valuation surveys in Developing Countries. World Development. 26(1), 21-30.

World Bank, 2004. World Bank Group's Program for Water Supply and Sanitation. Unpublished report, Water Supply and Sanitation Sector Board. 
Table 1: Example choice card

\begin{tabular}{|l|c|c|c|}
\hline & Option 1 & Option 2 & Current situation \\
\hline Extra days per week & 2 & 1 & 0 \\
Increase in monthly water bill & Birr 10 & Birr 3 & Birr 0 \\
\hline I prefer & $\square$ & $\square$ & $\square$ \\
\hline
\end{tabular}


Table 2: Key demographic and water supply characteristics of the sample population

\begin{tabular}{lcccc}
\hline Characteristic & Mean & St. dev. & Min. & Max. \\
\hline Share female respondents & 0.63 & 0.48 & 0 & 1 \\
Average age & 33.9 & 6.0 & 18 & 80 \\
Average household size & 5.6 & 3.3 & 1 & 21 \\
Household income (Ethiopian Birr/month ${ }^{1}$ ) & 2388 & 1665 & 50 & 8000 \\
Average daily water consumption (liters) & 99.2 & 87.3 & 10 & 800 \\
Average number of days water supply & 4.1 & 1.7 & 1 & 7 \\
Average monthly water bill (Birr ${ }^{1}$ ) & 36.2 & 31.2 & 2.0 & 210.0 \\
Average monthly aversion costs (Birr ${ }^{1}$ ) & 32.1 & 57.2 & 0 & 252 \\
\hline
\end{tabular}


Table 3: Estimated choice models

\begin{tabular}{|c|c|c|c|c|}
\hline \multirow[b]{2}{*}{ Variable } & \multicolumn{2}{|c|}{$\begin{array}{l}\text { Model including water } \\
\text { supply characteristics }\end{array}$} & \multicolumn{2}{|c|}{$\begin{array}{c}\text { Model including } \\
\text { household characteristics }\end{array}$} \\
\hline & $\begin{array}{c}\text { Coefficient } \\
\text { estimate }\end{array}$ & $\begin{array}{c}\text { Standard } \\
\text { error }\end{array}$ & $\begin{array}{l}\text { Coefficient } \\
\text { estimate }\end{array}$ & $\begin{array}{c}\text { Standard } \\
\text { error }\end{array}$ \\
\hline ASC & $2.611^{* * * *}$ & 0.425 & $1.516^{* * * *}$ & 0.464 \\
\hline Water supply (1,2,3 extra days/week) & $1.309^{* * *}$ & 0.134 & $0.826^{* * *}$ & 0.099 \\
\hline Standard deviation (Normal distributed) & $0.792^{* * *}$ & 0.218 & $0.417^{* * *}$ & 0.089 \\
\hline Water quality (dummy: no boiling) & $4.805^{* * *}$ & 0.588 & $1.954^{* * *}$ & 0.289 \\
\hline Standard deviation (Uniform distributed) & $7.900^{* * *}$ & 1.105 & $2.758^{* * *}$ & 0.272 \\
\hline Water bill $(3,5,10,15,20$ Birr/month) & $-0.251^{* * *}$ & 0.017 & $-0.195^{* * *}$ & 0.008 \\
\hline ASC $x$ household income (Birr/month) & - & & $0.0004^{* * *}$ & 0.0001 \\
\hline Water supply x living in Misrak Wukro & & & $0.296^{* *}$ & 0.145 \\
\hline Water quality x female respondents & - & & $0.822^{* *}$ & 0.345 \\
\hline Water quality $\mathrm{x}$ aversion costs (Birr/month) & - & & $0.011^{* * *}$ & 0.005 \\
\hline Sigma error component & $3.191^{* * *}$ & 0.523 & $3.240^{* * *}$ & 0.409 \\
\hline Log likelihood function & -1260.349 & & -1158.358 & \\
\hline McFadden pseudo R-squared & 0.341 & & 0.394 & \\
\hline $\mathrm{N}$ & 1740 & & 1740 & \\
\hline
\end{tabular}


Table 4: Test results equality of preference $(\beta)$ and scale $(\mu)$ parameters between choice tasks

\begin{tabular}{|c|c|c|c|c|c|c|c|c|c|c|c|}
\hline & $\begin{array}{l}\text { Comparison } \\
\text { choice tasks (t) }\end{array}$ & $\mathbf{L} \mathbf{L}_{\mathbf{t} \mathbf{i}}$ & $\mathbf{L} \mathbf{L}_{\mathbf{t} \mathbf{j}}$ & $\begin{array}{c}\mathbf{L L}_{\mathrm{ti+j}} \\
\left(\mu_{\mathrm{ti}} \neq \mu_{\mathrm{tj}}\right)^{\mathrm{a}}\end{array}$ & $\begin{array}{l}\text { LR-test } \\
\text { (10 d.f.) }\end{array}$ & $\begin{array}{c}\text { Reject } \\
\mathbf{H}_{0}: \beta_{\mathrm{ti}}=\beta_{\mathrm{tj}} ?\end{array}$ & $\begin{array}{c}\text { Relative scale } \\
\qquad\left(\mu_{\mathrm{tj}} / \mu_{\mathrm{ti}}\right)\end{array}$ & $\begin{array}{c}\text { Relative var. } \\
\left(\sigma_{\mathrm{tj}}^{2} / \sigma_{\mathrm{ti}}^{2}\right)\end{array}$ & $\begin{array}{c}\mathbf{L L}_{\mathrm{ti}+\mathbf{j}} \\
\left(\mu_{\mathrm{ti}}=\mu_{\mathrm{tj}}\right)^{\mathrm{b}}\end{array}$ & $\begin{array}{l}\text { LR-test } \\
\text { (1 d.f.) }\end{array}$ & $\begin{array}{c}\text { Reject } \\
\mathbf{H}_{0}: \mu_{\mathrm{ti}}=\mu_{\mathrm{tj}} ?\end{array}$ \\
\hline 1 & $1-3 \& 4-6$ & -270.001 & -313.504 & -605.149 & 43.29 & Yes & 1.40 & 0.51 & -605.484 & 0.67 & No \\
\hline 2 & $1-3 \& 7-9$ & -270.001 & -329.888 & -623.483 & 47.19 & Yes & 0.41 & 5.95 & -628.437 & 9.91 & Yes \\
\hline 3 & $1-3 \& 10-12$ & -270.001 & -239.144 & -564.342 & 110.40 & Yes & 4.01 & 0.06 & -569.474 & 10.26 & Yes \\
\hline 4 & $4-6 \& 7-9$ & -313.504 & -329.888 & -652.259 & 17.73 & Yes & 0.42 & 5.67 & -660.236 & 15.96 & Yes \\
\hline 5 & $4-6 \& 10-12$ & -313.504 & -239.144 & -586.327 & 67.36 & Yes & 1.83 & 0.30 & -590.800 & 8.95 & Yes \\
\hline 6 & $7-9 \& 10-12$ & -329.888 & -239.144 & -610.236 & 82.41 & Yes & 2.65 & 0.14 & -619.113 & 17.75 & Yes \\
\hline
\end{tabular}

LL: $\log$ likelihood; Likelihood Ratio (LR) tests performed at 10\% significance level.

a pooled mixed logit model with scale normalization; ${ }^{\text {b }}$ pooled mixed logit model without scale normalization. 
Table 5: Estimated WTP for water supply improvements per household per month

\begin{tabular}{|c|c|c|c|c|}
\hline \multirow{3}{*}{ Policy scenario } & \multirow{2}{*}{\multicolumn{2}{|c|}{$\begin{array}{c}\text { Without water quality } \\
\text { improvement }^{1}\end{array}$}} & \multirow{2}{*}{\multicolumn{2}{|c|}{$\begin{array}{c}\text { With water quality } \\
\text { improvement }^{2}\end{array}$}} \\
\hline & & & & \\
\hline & Birr & $U S D$ & Birr & $U S D$ \\
\hline \multirow[t]{2}{*}{1 extra day per week water } & 9.8 & 0.6 & 21.3 & 1.3 \\
\hline & (1.7) & $(1.0)$ & (1.8) & $(0.1)$ \\
\hline \multirow[t]{2}{*}{2 extra days per week water } & 13.8 & 0.8 & 25.3 & 1.5 \\
\hline & $(2.7)$ & $(0.2)$ & $(2.5)$ & $(0.1)$ \\
\hline \multirow[t]{2}{*}{3 extra days per week water } & 17.9 & 1.1 & 29.4 & 1.8 \\
\hline & (1.8) & $(0.1)$ & (7.1) & $(0.4)$ \\
\hline
\end{tabular}

